\title{
Parvalbumin immunoreactivity during the development of the cerebellum of the rainbow trout
}

Angel Porteros, Rosario Arévalo, Jesús G. Briñón, Carlos Crespo, José Aijón and José R. Alonso

Departamento de Biología Celular y Patología. Universidad de Salamanca. E-37007 Salamanca. Spain.

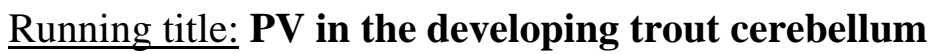

Number of pages: 15

Number of figures: 2

Correspondence to be sent to:

Dr. José R. Alonso.

Departamento de Biología Celular y Patología.

Universidad de Salamanca.

Facultad de Medicina. C/ Alfonso X el Sabio, s/n. E-37007 Salamanca. Spain.

Phone:+34-23-294400 ext. 1854

Fax: +34-23-294549

E-mail: jralonso@gugu.usal.es

Acknowledgements:

The authors thank Dr. M.R. Celio (Fribourg, Switzerland) for kindly providing the anti-PV antibody used in this study. This work was supported by funds from the DGICyT (PB94-1388) and the Junta de Castilla y León. 


\section{ABSTRACT}

The distribution of parvalbumin immunoreactivity in the developing cerebellum of the rainbow trout was studied by using a specific monoclonal antibody and the avidin-biotin peroxidase method. Parvalbumin immunoreactivity was absent during the embryonic development of the cerebellum. The first immunoreactive elements, identified by their localization and posterior morphological evolution as immature Purkinje cells, appeared at 6 days posthatching in the presumptive corpus cerebelli and lobus vestibulolateralis. The labeling extended throughout the cerebellum following a caudorostral gradient, and in 21 days alevins, parvalbumin immunoreactive Purkinje cells were also observed in the valvula cerebelli. The appearance of PV-immunostaining in the Purkinje cells was not simultaneous; the labeling was observed initially in the cell body, extending gradually to the dendritic branches and finally to the axon. From one year onwards, parvalbumin immunoreactive terminal puncta from the Purkinje cell axons were observed surrounding the cell bodies of eurydendroid cells, that were parvalbumin immunonegative in all developmental stages studied. The spatio-temporal pattern of parvalbumin immunoreactivity in the rainbow trout cerebellum is different to previous observations in the cerebellum of amniotes.

\section{CLASSIFICATION TERMS}

Theme A: Development and regeneration

Topic: Motor systems

\section{KEY WORDS}

Calcium, Cerebellum, Development, Fish, Parvalbumin, Purkinje cells 


\section{Introduction}

Calcium is an ubiquitous and important second messenger for intracellular processes including many cellular events in neural development $[18,19]$. Thus, this ion is involved in the movements that led to the folding of the neural crest and neurulation [2], it modulates the successive cell divisions during the proliferation period [11], and it is also involved in cell migration [5]. During the nerve cell growth and its maturation, an optimal development only takes place in a narrow intracellular calcium range $[3,12,13]$.

Calcium effects are modulated intracellularly by different mechanisms including the so-called calcium-binding proteins. Some of these proteins share a structural motif for calcium binding, the EF-hand domain. This sequence was firstly described from parvalbumin (PV), the first EF-hand protein isolated and crystallized [16]. PV binds intracellular free calcium with dissociation constants in the micromolar range [23] which suggests that it has physiologically important storage and buffering properties [8]. Though the precise function of PV in neurons is unknown, its expression is believed to be associated with metabolically and electrically active fast-firing neurons $[6,14]$. PV is also a selective marker for particular groups of neurons in the Central Nervous System of amniotes [6] and anamniotes [1,4].

During embryonic development, teleostean cerebellum originates from the alar plate, and finally from the rhombic lip, at the wall of the fourth ventricle [25]. It organizates in the most precocious stages in a primordial cerebellar body (cerebellar plate) and paired lateral auricles $[17,25]$. The adult cerebellum comprises three main areas: the folded valvula cerebelli, originated from the rostralmost portion of the cerebellar anlage; the massive corpus cerebelli; and the transversely oriented lobus vestibulolateralis, originated from the lateral expansions of the cerebellar anlage. These regions are laminated structures, with a superficial molecular layer, an intermediate monostratified layer of Purkinje cells and a deep granule cell layer in the corpus cerebelli and lobus vestibulolateralis, whereas the organization is reversed in the valvula cerebelli [10]. Although the basic structure of the cerebellum is common in all vertebrates, important anatomical and cytoarchitectonical 
differences exists between teleosts and amniote vertebrates. These include the presence in teleosts of the valvula cerebelli [20], and the absence of efferent deep cerebellar nuclei [22], whereas an exclusive neuronal type, the eurydendroid cell, located just beneath the Purkinje cell layer, is the efferent element of teleostean cerebellum [10].

In this work we analyze the evolution of PV immunolabeling during the development of the cerebellum of the rainbow trout. The study of the immunocytochemical distribution of this protein during the ontogeny may shed new light on its function during brain development. In addition, we have compared our results with previous data on the distribution of PV during the ontogeny of mammalian cerebellum, in order to determine the divergence in the expression of this calcium binding-protein along the phylogeny.

\section{Material and methods}

Fertilized eggs of rainbow trout Oncorhynchus mykiss (Walbaum, 1792) (Salmonidae, Teleostei) were obtained from a local breeder (Galisancho, Salamanca) and transferred to freshwater aquaria at $10^{\circ} \mathrm{C}$ on a $12: 12 \mathrm{~h}$ light:dark cycle. After hatching, fry and juvenile rainbow trouts were kept under the same conditions. Developmental stages are given in day-degrees (dd) for embryos and in days after hatching (D) for fry and juveniles [24]. Three animals of each of the following stages were used: $250 \mathrm{dd}, 300 \mathrm{dd}, 350 \mathrm{dd}, 3 \mathrm{D}$, 6 D, 21 D, 30 D, 90 D and 180 D. Three one year old juveniles, and three adults (three years old), weighing 150-300 g, were obtained from the same source and processed immediately.

\section{Tissue preparation}

Animals were anesthetized with 0.03\% tricaine methanesulphonate (MS-222 Sigma) and subsequently processed by different methods depending on their ages.

Embryos (250, 300, and 350 dd) and fry (3, 6, 21 and 30 D) were fixed by immersion in $4 \%$ paraformaldehyde and 2\% picric acid in $\mathrm{PB}$ for $4 \mathrm{~h}$, washed in $\mathrm{PB}$ and immersed in $30 \%$ sucrose $(w / v)$ in PB for cryoprotection. 
Juveniles (90 D, $180 \mathrm{D}$ and one year) and adults were perfused transcardially with $0.63 \% \mathrm{NaCl}$ solution followed by a fixative containing $4 \%$ paraformaldehyde and $2 \%$ picric acid in PB. The brains were removed from the skull, postfixed in the same fixative for $4 \mathrm{~h}$ and immersed in PB containing 30\% sucrose (w/v) overnight for cryoprotection.

Coronal sections were cut at $20 \mu \mathrm{m}$ on a Leica cryostat, thawmounted on chromealum-gelatinized slides and processed for immunohistochemistry following the avidin-biotin-peroxidase method.

\section{Immunohistochemistry}

Tissue was preincubated with 10\% normal horse serum and $0.1 \%$ Triton X-100 in PB for $1 \mathrm{~h}$ at $4^{\circ} \mathrm{C}$. Thereafter, the tissue was incubated with anti-PV serum (1:1,000 in PB) for two days at $4^{\circ} \mathrm{C}$. After washing in $\mathrm{PB}$, tissue was incubated with biotinylated horse antimouse immunoglobulin G (Vector Labs.; 1:200 in PB) for $1 \mathrm{~h}$ at room temperature and then in avidin-biotin-peroxidase complex (Vector Labs; 1:225 in PB) for 2 h. Tissue-bound peroxidase was visualized by incubating the sections with $0.07 \% 3,3$ '-diaminobenzidine (Sigma) and $0.003 \% \mathrm{H}_{2} \mathrm{O}_{2}$ in $0.1 \mathrm{M}$ Tris- $\mathrm{HCl}$ buffer ( $\mathrm{pH}$ 7.6). The course of the reaction was controlled under the microscope. After rinsing with PB, sections were dehydrated through a graded ethanol series, cleared with xylene, and coverslipped using Entellan (Merck). Maximum diameters of fifty cells per stage were measured using a Zeiss ocular micrometer, and the mean \pm the standard error of the mean is indicated for the cells in each stage. For the measurement of cell sizes, only well defined neurons located in the middle of the thickness of the section and showing the main dendritic trunk were selected.

\section{Controls}

The primary anti-PV antibody used has been fully characterized [7] and previously used in mammalian [6] and teleostean [1,4] brains. The immunostaining procedure was controlled by omitting the primary antibody, and no residual staining was observed. 
Endogenous peroxidase activity was blocked by the application of $0.3 \%$ hydrogen peroxide diluted in methanol for 30 min before the incubation with the primary antibody.

\section{Results}

No PV immunoreactivity was observed in the rainbow trout cerebellum in any of the embryonic stages studied. PV expression was firstly detected at the $6 \mathrm{D}$ stage. In this initial stage, slightly stained cells were observed at the dorsocentral regions of the cerebellar plate (presumptive corpus cerebelli), and of the presumptive lobus vestibulolateralis (Fig. 1a). PV-immunostained elements were not observed in the rostralmost portion of the cerebellum, the valvula cerebelli. The PV-labeled cells had round or oval somata, of $7.86 \pm$ $0.76 \mu \mathrm{m}$ of maximum diameter, and PV immunoreactivity was observed only in the cell body, with no stained prolongations (Fig. 1b). Due to their posterior localization and morphological evolution, these cells were identified as immature Purkinje cells.

Progressively, the PV immunolabeling extended throughout the cerebellum from caudal to rostral regions. At the stage of $21 \mathrm{D}$, in addition to a higher number of PVimmunolabeled Purkinje cells in corpus cerebelli and lobus vestibulolateralis, we observed PV-immunoreactive Purkinje cells in the valvula cerebelli. Cell bodies increased their size in this stage (9.12 $\pm 0.69 \mu \mathrm{m}$ of maximum diameter) but stained prolongations were still not observable. However, a pale diffuse brownish precipitate could be observed at the molecular layer where the dendrites of Purkinje cells arborize (Fig. 1c). At 30 D, the PV immunostaining extended to the whole rostrocaudal extent of the cerebellum (i.e. valvula cerebelli, corpus cerebelli and lobus vestibulolateralis). PV immunoreactivity was observed in Purkinje cells somata (11.24 \pm 0.72 of maximum diameter), but also, and for the first time, in primary dendritic trunks located in the molecular layer (Fig. 1d). In the 90 D stage, PVimmunolabeled Purkinje cells have increased the size of the cell body (12.86 $\pm 0.45 \mu \mathrm{m}$ of maximum diameter). PV-immunoreactivity extended to longer portions of the dendrites, that 
were disposed in a palisade through the molecular layer, extending from the somata perpendicularly to the cerebellum surface (Fig. 1e). In 180 D juveniles, Purkinje cells increased in number and size of the somata (17.3 $\pm 0.83 \mu \mathrm{m}$ of maximum diameter), and also in PV-immunostaining intensity. Their complete dendritic arborization was PV immunostained at this stage, forming a dense network of PV-immunoreactive prolongations whithin the molecular layer (Fig. 1f).

In one year old juvenile animals and in adults we observed the definitive PV immunoreactivity pattern in the cerebellum of the rainbow trout. Purkinje cells acquired their definitive size (26.89 \pm 0.74 ), were intensely stained in the valvula cerebelli (Fig. 2a), corpus cerebelli and lobus vestibulolateralis (Fig. 2b), showing round, oval or piriform somata, with completely PV-immunostained dendritic trunks in the molecular layer, where they ramified profusely (Fig. 2c). In previous stages we could not observe PV-immunoreactivity in any axonic prolongation. By contrast, in one year juveniles and adults, the axon hillock was observed arising from the basal pole of the cell body (Fig. 2e) and it could be followed crossing towards the granule cell layer. In some sections, the Purkinje cell axons coursed horizontally along the Purkinje cell layer for a distance, and abundant PV-immunostained axonal plexuses were observed within the granule cell layer (Fig. 2d). Close to the Purkinje cells we found PV immunopositive Purkinje axon terminals, that surrounded the PV immunonegative cell bodies and initial portions of the dendritic tree of the eurydendroid cells, located just beneath the Purkinje cell layer (Fig. 2e, f).

\section{Discussion}

Our results in the cerebellum of adult rainbow trout are coincident to those obtained by Alonso et al. [1] in both the rainbow trout and the Mediterranean barbel (Barbus meridionalis). The unique cellular elements that display PV immunoreactive in the trout cerebellum are the Purkinje cells. By contrast, in addition to Purkinje cells, stellate cells and basket cells are also PV immunoreactive in the mammalian cerebellum [6,29]. All Purkinje 
cells are PV immunoreactive in the rainbow trout ([1] and present report) as in the barbel [1], chick [26], rat [6,26] and human [29]. Thus, the presence of PV in Purkinje cells in the whole cerebellum is a constant feature throughout the phylogenetic scale. However, in the tench, a cyprinid teleost, only the Purkinje cells located in the lobus vestibulolateralis and medial part of the valvula cerebelli display PV immunoreactivity, whereas those in the corpus cerebelli and lateral part of the valvula cerebelli are PV-immunonegative [9]. This heterogeneity in the PV expression might indicate specific functional implications of different groups of Purkinje cells in tench that are not present in other species such as the rainbow trout.

Purkinje cells are not the efferent elements of the teleostean cerebellum. They connect with an exclusive cell type, the eurydendroid cell [10]. Eurydendroid cells send directly their axons to tegmental regions, to the lateral line nuclei, and to the spinal cord, among others [10]. In spite of the cytoarchitectonical differences between teleostean and mammalian cerebellum, the pattern of PV immunoreactivity seems to be conserved throughout evolution. Thus, Purkinje cells are PV immunoreactive in both teleosts and mammals. In addition, PV immunonegative eurydendroid cells are innervated by PV immunoreactive axons from the Purkinje cells. According to their function in the cerebellar circuitry, eurydendroid cells are considered homologous to the deep cerebellar nuclei neurons of mammals [21], that are also PV-immunonegative and receive PV immunopositive inputs from the Purkinje cells $[6,26]$.

The axons of Purkinje cells are formed at initial stages of the fry development of the rainbow trout, and the collaterals of Purkinje cell axons on the eurydendroid cells are observed four days after hatching [25]. Then, calcium-dependent mechanisms involved in the growing of axonal prolongations, establishment of connections and transduction of the nervous signal are active at this stage of development. Although it has been reported by quantitative analysis using immunogold labeling that axons and axon terminals of Purkinje cells have higher levels of PV than somata and dendrites in the rat cerebellum [15], we did not detect PV immunoreactivity in the axons nor in the terminal boutons on the eurydendroid 
cells until the one year stage. This differential intracellular localization of PV during the Purkinje cell development, with a too low PV amount in the axons to be immunohistochemically detected, might indicate a less significance of PV in calcium buffering within the axons than in somata in the initial stages of development of the Purkinje cells of the rainbow trout.

Although the developmental stages are not easily comparable, the onset and evolution of the PV expression in Purkinje cells seem to be more precocious in mammals than in teleosts. In rat cerebellum, PV expression initiates during the embryonic development in Purkinje cells [27], and 4 days after born all these cells display PV immunoreactivity. In human cerebellum, PV immunoreactivity appears at the 16th week of gestation in Purkinje cells, the intensity of the immunostaining increases progressively, and an intricate PVimmunoreactive dendritic tree is observed in the Purkinje cells at the 28th week of gestation [29]. By contrast, we have observed PV immunolabeling in the rainbow trout cerebellum for the first time 6 days after hatching, PV-immunoreactive dendrites are observed from 30 days after hatching onwards, and the definitive pattern is acquired in a late juvenile stage.

During mammalian development, $\mathrm{PV}$ is expressed when morphogenetic migration and neuronal differentiation are completed, and it has been suggested that the onset of PV expression is associated with the start of physiological activity of specific neuronal populations, when they have concluded their differentiation [27]. By contrast, PVimmunoreactivity has a posthatching onset in the rainbow trout cerebellum. These differences are particularly suggestive, considering that a newly-hatched rainbow trout has developed motor skills that conduce to an active swimming by caudal propulsion, and cerebellar systems involved in motor control of swimming are already functional [28]. During ontogeny of the rainbow trout, development of the valvula cerebelli lags significantly behind that of the other cerebellar structures (corpus cerebelli and lobus vestibulolateralis) [25]. In agreement, our results demonstrate that PV immunoreactivity appears earlier in the corpus cerebelli and lobus vestibulolateralis than in the valvula cerebelli. The progressive extension of the PV immunoreactivity until the definitive pattern correlates with the 
processes of cerebellar morphogenesis, which conduce to the improvement of swimming performance in juveniles and adults [28]. 


\section{ABBREVIATIONS}

CC: corpus cerebelli

D: days after hatching

dd: day-degrees

gr: granule cell layer

LV: lobus vestibulolateralis

mol: molecular layer

Pu: Purkinje cell layer

PV: parvalbumin

$\mathrm{V}$ : ventricle

VC: valvula cerebelli 


\section{REFERENCES}

[1] Alonso, J.R., Arévalo, R., Briñón, J.G., Lara, J., Weruaga, E. and Aijón, J., Parvalbumin immunoreactive neurons and fibres in the teleost cerebellum, Anat. Embryol., 184 (1992) 355-361.

[2] Anglister, L., Farber, I.C., Shahar, A. and Grinvald, A., Localization of voltage-sensitive calcium channels along developing neurites: their possible role in regulating neurite elongation, Dev. Biol., 94 (1982) 351-365.

[3] Angus Silver, R., Lamb, A.G. and Bolsover, S.R., Elevated cytosolic calcium in the growth cone inhibits neurite elongation in neuroblastoma cells: correlation of behavioral states with cytosolic calcium concentration, J. Neurosci., 9 (1989) 4007-4020.

[4] Briñón, J.G., Alonso, J.R., García-Ojeda, E., Arévalo, R., Porteros, A., Velasco, A. and Aijón, J., Parvalbumin immunoreactivity in the telencephalic hemispheres of the tench, Tinca tinca, Arch. Ital. Biol., 132 (1994) 1-12.

[5] Campbell, A.K., Intracellular Calcium, John Wiley, Chichester, 1983.

[6] Celio, M.R., Calbindin D-28k and parvalbumin in the rat nervous system, Neuroscience, 35 (1990) 375-475.

[7] Celio, M.R., Baier, W., de Viragh, P., Schärer, L. and Gerday, C., Monoclonal antibodies directed against the calcium binding protein parvalbumin, Cell Calcium, 9 (1988) 81-86.

[8] Chard, P.S., Bleakman, D., Christakos, S., Fullmer, C.S. and Miller, R.J., Calcium buffering properties of calbindin D-28k and parvalbumin in rat sensory neurones, $J$. Physiol. Lond., 472 (1993) 341-357.

[9] Crespo, C., Estudio neuroquímico de la expresión de proteínas ligantes de calcio en las poblaciones celulares nitrérgicas del encéfalo de teleósteos de agua dulce. Doctoral Thesis, 1998, University of Salamanca.

[10] Finger, T.E., Organization of the teleost cerebellum. In R.J. Northcutt and R.E. Davis (Eds.), Fish Neurobiology, Vol. I: Brain Stem and Sense Organs, The University of Michigan Press, Ann Arbor, 1983, pp. 261-284.

[11] Hepler, P.K., The role of calcium in cell division, Cell Calcium, 16 (1994) 322-330. 
[12] Kater, S.B., Mattson, M.P., Cohan, C. and Connor, J., Calcium regulation of the neuronal growth cone, Trends Neurosci., 11 (1988) 315-321.

[13] Kater, S.B. and Mills, L.R., Regulation of growth cone behavior by calcium, J. Neurosci., 11 (1991) 891-899.

[14] Kawaguchi, Y., Kosaka, T., Heizmann, C.W. and Hama, K., Fast spiking cells in the hippocampus (CA1 region) contain the calcium binding protein parvalbumin, Brain Res., 416 (1987) 369-374.

[15] Kosaka, T., Kosaka, K., Nakayama, T., Hunziker, W. and Heizmann, C.W., Axons and axon terminals of cerebellar Purkinje cells have higher levels of parvalbumin immunoreactivity than somata and dendrites: quantitative analysis by immunogold labeling, Exp. Brain Res., 93 (1993) 483-491.

[16] Kretsinger, R.H. and Kockolds, C.E., Carp muscle calcium-binding protein. Structure determination and general description, J. Biol. Chem., 248 (1973) 3313-3326.

[17] Kuhlenbeck, H., The Central Nervous System of Vertebrates, S. Karger, Basel, 1973.

[18] Mattson, M.P., Cellular signaling mechanisms common to the development and degeneration of neuroarchitecture. A review, Mechan. Ageing Dev., 50 (1988) 103-159.

[19] Matsson, M.P., Calcium as sculptor and destroyer or neural circuitry, Exp. Gerontol., 27 (1992) 29-49.

[20] Meek, J. and Nieuwenhuys, R., Palisade pattern of mormyrid Purkinje cells: a correlated light and electron microscopic study, J. Comp. Neurol., 306 (1991) 156-192.

[21] Nieuwenhuys, R. and Nicholson, C., Aspects of the histology of the cerebellum of mormyrid fishes. In R. Llinás (Ed.), Neurobiology of Cerebellar Evolution and Development, Am. Med. Assoc., Chicago, 1969, pp. 135-169.

[22] Nieuwenhuys, R., Pouwels, E. and Smulders-Kersten, E., The neuronal organization of cerebellar lobe C1 in the mormyrid fish Gnathonemus petersii (Teleostei)., Z. Anat. Entwicklungsgesch., 144 (1974) 315-336.

[23] Persechini, A., Moncrief, N.D. and Kretsinger, R.H., The EF-hand family of calciummodulated proteins, Trends Neurosci., 12 (1989) 462-467. 
[24] Porteros, A., Arévalo, R., Weruaga, E., Crespo, C., Briñón, J.G., Alonso, J.R. and Aijón, J., Calretinin immunoreactivity in the developing olfactory system of the rainbow trout, Dev. Brain Res., 100 (1997) 101-109.

[25] Pouwels, E., On the development of the cerebellum of the trout, Salmo gairdneri. I. Patterns of cell migration, Anat. Embryol., 152 (1978) 291-308.

[26] Rogers, J.H., Immunoreactivity for calretinin and other calcium-binding proteins in cerebellum, Neuroscience, 31 (1989) 711-721.

[27] Solbach, S. and Celio, M.R., Ontogeny of the calcium binding protein parvalbumin in the rat nervous system, Anat. Embryol., 184 (1991) 103-124.

[28] Toyoda, J. and Uematsu, K., Brain morphogenesis of the red sea bream, Pagrus major (Teleostei), Brain Behav. Evol., 44 (1994) 324-337.

[29] Yu, M.C., Cho, E., Luo, C.B., Li, W.W.Y., Shen, W.Z. and Yew, D.T., Immunohistochemical studies of GABA and parvalbumin in the developing human cerebellum, Neuroscience, 70 (1996) 267-276. 


\section{FIGURE LEGENDS}

\section{Figure 1}

a.- Overview of the PV immunolabeling in the corpus cerebelli (CC) and lobus vestibulolateralis (LV) at $6 \mathrm{D}$ stage. Scale bar $=100 \mu \mathrm{m}$

b.- Immature Purkinje cells showing weakly PV immunostaining in the lobus vestibulolateralis. $6 \mathrm{D}$ fry. Scale bar $=25 \mu \mathrm{m}$

c.- PV immunostaining in the Purkinje cells of the valvula cerebelli. Labeled dendrites are not distinguishable in the molecular layer. $21 \mathrm{D}$ fry. gr: granule cell layer. mol: molecular layer. Pu: Purkinje cell layer.Scale bar $=50 \mu \mathrm{m}$

d.- PV immunoreactivity in the lobus vestibulolateralis of a $30 \mathrm{D}$ fry. Purkinje cell somata and dendrites are observed. No immunolabeling is present in the granule cell layer. gr: granule cell layer. mol: molecular layer. Pu: Purkinje cell layer. Scale bar $=50 \mu \mathrm{m}$

e.- Corpus cerebelli of a 90 D juvenile. Purkinje cells are PV immunoreactive in the whole dorsoventral extention. gr: granule cell layer. mol: molecular layer. Pu: Purkinje cell layer. Scale bar $=100 \mu \mathrm{m}$

f.- PV immunoreactive Purkinje cells in the valvula cerebelli (VC) of a 180 D juvenile. V: ventricle. Scale bar $=100 \mu \mathrm{m}$

\section{Figure 2}

a.- PV immunoreactivity in the adult valvula cerebelli. Purkinje cell somata and dendrites are located in the innermost region. gr: granule cell layer. mol: molecular layer. Pu: Purkinje cell layer. V: ventricle. Scale bar $=500 \mu \mathrm{m}$

b.- General view of the corpus cerebelli (CC) and lobus vestibulolateralis (LV) of an adult rainbow trout. All Purkinje cells in both regions are PV immunoreactive. Scale bar $=250 \mu \mathrm{m}$ c.- PV immunostained Purkinje cells in the corpus cerebelli of an adult rainbow trout. Cell bodies are arranged in a monocellular layer, and dendritic trees arborize in the molecular layer. Scale bar $=50 \mu \mathrm{m}$ 
d.- Dense group of PV-immunopositive axons just under the Purkinje cell layer (arrows) in the lobus vestibulolateralis. A negative eurydendroid cell can also be observed impinged by PV-immunoreactive boutons (open arrow). Scale bar $=50 \mu \mathrm{m}$

e.- Detail of PV immunostaining in the adult corpus cerebelli. Purkinje cell axon hillock can be observed (open arrows). Terminal puncta surrounding PV-immunonegative eurydendroid cells dendrite and somata can also be distinguished (arrows). Scale bar $=50 \mu \mathrm{m}$ 
